\title{
EFFECTS OF ETHYLAMINE ON THE CRYSTAL GROWTH OF HYDROXYAPATITE
}

\section{FUKUE NAGATA， YOSHIYUKI YOKOGAWA, MOTOHIRO TORIYAMA, YUKARI KAWAMOTO, TAKAHIRO SUZUKI, KAORI NISHIZAWA and TETSUYA KAMEYAMA}

\author{
Bioceramics Laboratory \\ National Industrial Research Institute of Nagoya \\ Hirate-cho, Kita-ku, Nagoya 462 JAPAN
}

\begin{abstract}
Plate-like hydroxyapatite (HAp) crystals whose preferential crystal plane is the $a$-plane were obtained by hydrothermal treatment in the presence of ethylamine. The HAp precursor slurry was treated hydrothermally with various amount of ethylamine at $200{ }^{\circ} \mathrm{C}$ for 5 hours. TEM revealed that the products synthesized with $5 \mathrm{wt} \%$ or more ethylamine are plate-like crystals, in contrast the products obtained without ethylamine has a granular or rod-like shape. XRD patterns of plate-like crystals orientated preferentially indicate that the grown face of the plate-like crystals is a-plane of HAp. It can be suggested that ethylamine captured $\mathrm{PO}_{4}{ }^{3-}$ ions in the solution by chelation and retarded a supply of $\mathrm{PO}_{4}{ }^{3-}$ to HAp nuclei and consequently crystal growth along a particular axis was inhibited.
\end{abstract}

\section{INTRODUCTION}

Hydroxyapatite $\left(\mathrm{Ca}_{10}\left(\mathrm{PO}_{4}\right)_{6}(\mathrm{OH})_{2} ; \mathrm{HAp}\right)$ has been attracting attention as the material for column packing of liquid chromatography to separate and/or purification of protein $^{1}$, because of the adsorptive properties of HAp. Protein tends to adsorb on a specific crystal plane of $\mathrm{HAp}^{2}$. As a consequence, recent studies concerned with the morphology control of HAp crystals have become an extremely important part of HAp research due to the insight such investigation can give into the improvement of the adsorption and/or purification characteristics for protein. While, participation of biopolymer in crystal growth, orientation and nucleation of mineralization in the body such as bone formation has also been interesting. In this laboratory, the morphology control of HAp crystals was studied by hydrothermal synthesis in the presence of alcohols containing hydroxy groups, with special attention being paid to the effect of hydroxy groups on crystal growth of $\mathrm{HAp}^{3-4}$.

In the present paper, this theme was extended by investigating the morphology control by hydrothermal method in the presence of ethylamine containing amino group which is another functional group consisting in biopolymer. 
The HAp precursor slurry was prepared as follows; $0.06 \mathrm{~mol} \mathrm{CaCO}_{3}$ and $0.09 \mathrm{~mol}$ $\mathrm{CaHPO}_{4} \cdot 2 \mathrm{H}_{2} \mathrm{O}$ were agitated in a pot mill using $500 \mathrm{~g} \mathrm{ZrO}_{2}$ balls and $200 \mathrm{ml} \mathrm{H}_{2} \mathrm{O}$ for 24 hours at 50 r.p.m. to yield the HAp precursor. Various amounts of ethylamine were added to the $200 \mathrm{ml}$ HAp precursor. This mixture was treated in an autoclave with stirring under hydrothermal conditions at $180{ }^{\circ} \mathrm{C}$ for 5 hours to crystallize the HAp.

Phases of products were analyzed by powder X-ray diffraction (XRD; MAC science, $\mathrm{MXP}^{3}$ ) which employed a graphite monochromated $\mathrm{CuK} \alpha$ radiation, operation at $20 \mathrm{kV}$ and $40 \mathrm{~mA}$. In order to determine the crystal plane grown extensively by XRD, the plate-like samples dispersed in ethanol was dropped onto a glass plate and dry to create an oriented layer. Infrared spectra (IR; JASCO, FT/IR-8000S) were measured of $\mathrm{KBr}$ pellets. The morphology of the particles was observed by transmission electron microscopy (TEM; JEOL, JEM-4000FX) at $300 \mathrm{kV}$. The Ca/P ratio of the products and the solution before hydrothermal treatment were determined by inductively coupled plasma emission spectroscopy (ICP, Seiko Denshi Kogyo, SPS7000A).

\section{RESULTS and DISCUSSION}

TEM photographs of the products synthesized hydrothermally with varying amount of ethylamine indicated that the shape of crystals changed by ethylamine added (Fig. 1). The products obtained without ethylamine addition were granular-like crystals, about 200 $\mathrm{nm}$ in size, while those prepared when $5 \mathrm{wt} \%$ or more ethylamine added to the HAp precursor were plate-like crystals, about $50-300 \mathrm{~nm}$ in size.

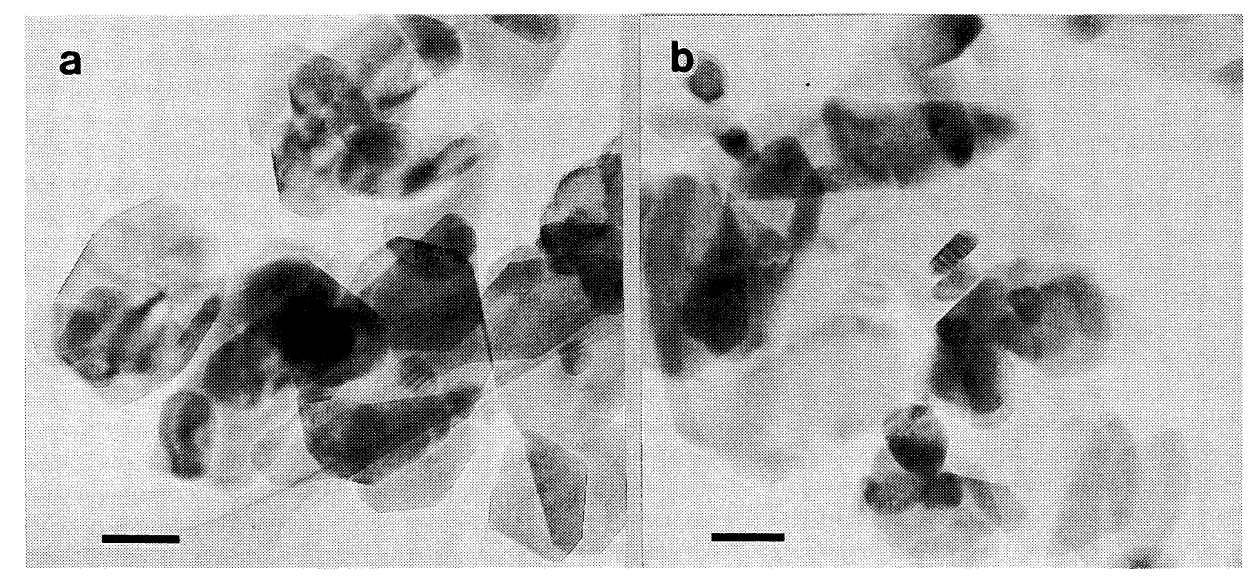

FIGURE 1. TEM micrographs of the products synthesized hydrothermally (a) without ethylamine and (b) with $10 \mathrm{wt} \%$ ethylamine. (scale shown represents $100 \mathrm{~nm}$ ) 
The peaks of XRD pattern of the precursor were broad, which indicated the precursor to be incompletely crystallized. The peaks of XRD patterns of the products treated hydrothermally with various amount of ethylamine were very sharp and the $d$ values of these peaks of those products were in good agreement with the JCPDS value of HAp (Fig. 2(a)). This indicated that the products were well crystallized HAp independently of amount of ethylamine added. Fig. 2(b) illustrates the X-ray diffraction patterns of the plate-like samples layered preferentially on the substrate glass. The peaks (100), (200) and (300) planes are apparently larger than those produced by the conventional powder X-ray diffractometry, shown in Fig. 2(a). From these results, the preferential crystal plane of plate-like products can be defined as the $a$-plane.

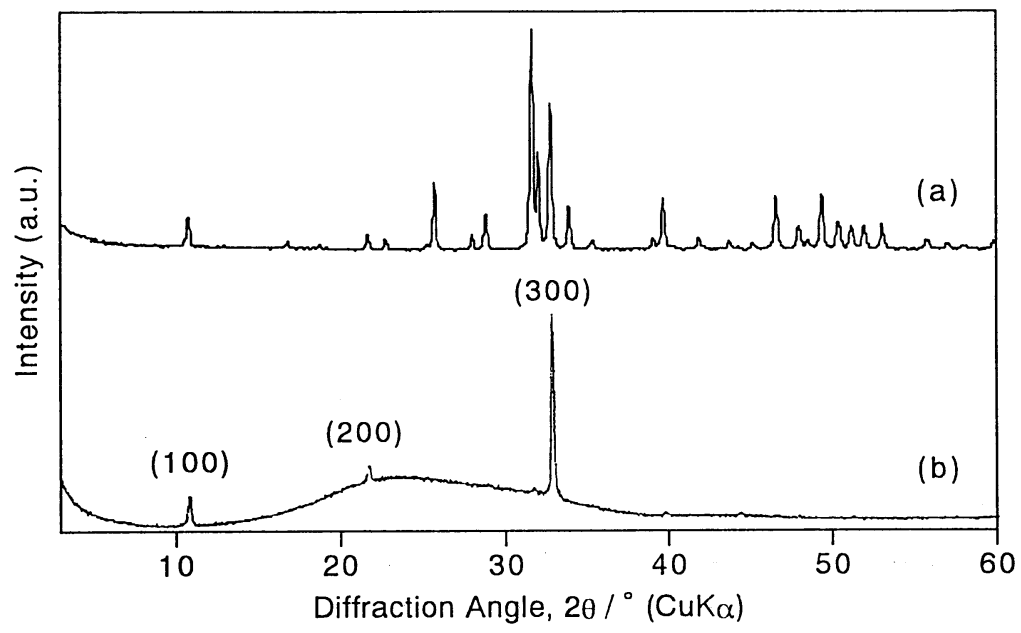

FIGURE 2. Powder X-ray diffraction pattern of (a) the random orientated plate-like product and (b) the preferentially orientated plate-like product. (The plate-like product was synthesized hydrothermally with $15 \mathrm{wt} \%$ methanol at $200{ }^{\circ} \mathrm{C}$ for 5 hours.)

TABLE. Ca/P ratio of the products synthesized hydrothermally and the ions in the solutions before synthesis.

\begin{tabular}{ccc}
\hline \multirow{2}{*}{$\begin{array}{c}\text { amount of ethylamine } \\
\text { added (wt \%) }\end{array}$} & \multicolumn{2}{c}{$\mathrm{Ca} / \mathrm{P}$ ratio } \\
\cline { 2 - 3 } & $\begin{array}{c}\text { products synthesized } \\
\text { hydrothermally }\end{array}$ & $\begin{array}{l}\text { ions in the solutions } \\
\text { before synthesis }\end{array}$ \\
\hline 0 & 1.657 & 7.047 \\
5 & 1.673 & 0.068 \\
15 & 1.685 & \\
50 & 1.689 & \\
\hline
\end{tabular}


ICP results showed that $\mathrm{Ca} / \mathrm{P}$ ratio of the products changed as a function of the amount of ethylamine added (Table). $\mathrm{Ca} / \mathrm{P}$ ratio of the products synthesized without ethylamine is 1.657, which is closed to that of stoichiometoric HAp. Addition of 50 wt $\%$ ethylamine led to increase $\mathrm{Ca} / \mathrm{P}$ ratios to 1.689 . On the other hand, $\mathrm{Ca} / \mathrm{P}$ ratios of the ions in the solutions filtrated from the slurry before hydrothermal treatment decreased and a marked increase of $\mathrm{P}$ concentration in the solution was observed, when ethylamine is added into the slurry. It can be explained from these results in the following way. Ethylamine captured $\mathrm{PO}_{4}{ }^{3-}$ ions in the solution by chelation and retarded a supply of $\mathrm{PO}_{4}{ }^{3-}$ to HAp nuclei. HAp crystals grew under the condition that $\mathrm{PO}_{4}{ }^{3-}$ were not supplied sufficiently, therefore crystal growth of HAp was inhibited along a particular axis.

\section{SUMMARY}

The summary of the results described on this paper are as follows.

(1) Plate-like HAp crystals whose preferential crystal plane is the $a$-plane with size 200 $\mathrm{nm}$ were have been synthesized hydrothermally with ethylamine at $200{ }^{\circ} \mathrm{C}$ for 5 hours.

(2) The amount of ethylamine required enough to obtain only plate-like crystals was at least $5 \mathrm{wt} \%$ in the HAp precursor slurry.

\section{REFERENCES}

1. T. Okuyama, T. Ogawa and M. Ebihara, Gypsum \& Lime, 210, 323-331 (1987).

2. T. Kawasaki, J Chromatogr., 157, 7-42 (1978).

3. F. Nagata, Y. Yokogawa, M. Toriyama, Y. Kawamoto, T. Suzuki and

K. Nishizawa, J. Ceram. Soc. Japan, 103, 70-73 (1995).

4. F. Nagata, Y Yokogawa, M Toriyama, Y. Kawamoto, T. Suzuki, K. Nishizawa and H. Nagae, Advanced Materials '93, II, 15A, 11-14 (1994). 